\title{
ASSISTENCIA DE ENFERMAGEM A PACIENTE COM COMPORTAMENTO DECORRENTE DE DISRITMIA CEREBRAL (PSICOSE EPILEPTICA)
}

* Maguida Costa Stefanelli

* Ilza Marlene Kuae Fukuda

* Hideko Takeuchi Forcella (relatora)

\begin{tabular}{l|l|}
\hline RBEn/08 \\
\hline
\end{tabular}

STEFANELLI, M.C. e Colaboradores - Assistência de enfermagem a paciente com comportamento decorrente de disritmia cerebral (psicsse epiléptica). Rev. Bras. Enf.; DF, $30: 128-135,1977$.

$\mathrm{Na}$ assistência de enfermagem em clínica psiquiátrica, dá-se ênfase ao comportamento expresso pelo paciente, principalmente ao nāo-verbal.

E indiscutível o valor da observação adequada das manifestaçōes de comportamento, para a equipe psiquiátrica: o enfermeiro baseia-se nos dados dessa observaçāo, para elaborar e avaliar a assistência dispensada ao paciente, e o médico vale-se deles, para suposiçāo diagnóstica, plano de tratamento e evoluçāo clínica.

Na literatura especializada, encontramos vários autores que destacam a importância da observação de comportamento com vistas à açāo da enfermagem. Em nosso meio, já se percebe a preocupação com o tema, por parte de alguns enfermeiros.
ARANTES (1972) coloca, como centro do ensino de Enfermagem Psiquiátrica, a observação do comportamento do paciente, a fim de conhecê-lo como pessoa e respeitar-lhe a individualidade. Considera a observação de comportamento do doente mental, uma das principais funçōes da enfermeira psiquiátrica e ressalta a conveniência de os demais membros da equipe serem inteirados a respeito.

Segundo TRAVELBEE (1969), o passo fundamental para a atuaçāo da enfermeira é a observação do paciente e a comunicação dela aos outros membros do grupo de trabalho. Acha nāo ser possível assistência de enfermagem adequada, sem uma observaçāo completa, clara, precisa e objetiva.

GARANT (1972) afirma que a observaçāo e a anotaçāo do comportamento

- Docentes da diciplina "Enfermagem Psiquiátrica" na Escola de Enfermagem da Universidade de săo Paulo. 
STEFANELI, M.C. e Colaboradores - Assistência de enfermagem a paciente com comportamento decorrente de disritmia cerebral (psicose epiléptica). Rev. Bras. Enf.; DF, $30: 128-135,1977$.

do enfêrmo são essenciais para identificar seus problemas e necessidades nãosatisfeitas. Enfatiza que o desenvolvimento de um plano de cuidado começa com a observação e avaliação sistemática do modo pelo qual o paciente se comporta.

De acordo com STEFANELLI \& ARANTES (1975), a observação e o relato objetivo das manifestações de comportamento auxiliam tanto na elucidação do diagnóstico médico e indicação terapêutica, como na elaboração do plano de assistência de enfermagem.

BROWN \& FOWLER e SLAVINSKY et al. (1969) mostram a importância da enfermeira comunicar, a toda a equipe, a observação de comportamento manifestado pelo doente. Com isso, salientam o valor da observação para o atendimento integral do paciente.

Para HOFLING et al. (1970), é a partir da observação das manifestaçōes de comportamento da pessoa enferma que se identificam as suas necessidades.

O trabalho de TUDOR (1970) provou a importância da observação acurada e contínua, para que se preste uma assistência de enfermagem adequada.

Segundo ARANTES (1968), a observação completa e objetiva é essencial na obtenção de dados completos que permitam identificar as necessidades básicas do paciente e planejar a assistência de enfermagem que lhe convém.

O ensino de Enfermagem Psiquiátrica, na Escola de Enfermagem da USP, centra-se na observação de comportamento do paciente, para que o estudante possa desenvolver uma assistência individualizada de enfermagem. Sabemos que muitos não acreditam na possibilidade dessa individualização. Todavia, este trabalho é o resultado do que vimos na prática, junto a estudantes que elaboraram planos e assistiram doentes com disritmia cerebral que manifestavam sintomas psiquiátricos - psicose epiléptica. A partir desses planos individualizados de assistência de enfermagem, tentamos elaborar um outro, geral, para assistir o enfermo internado em hospital psłquiátrico. Esperamas que o inverso possa ser feito, isto é, que este plano ofereça elementos para os enfermeiros elaborarem assistência individualizada aos pacientes com disritmia cerebral que apresentam sintomas psiquiátricos. Queremos ressaltar, entretanto, que as particularidades de cada um devem ser, sempre, consideradas. Para isso, será necessário que se faça, antes, uma observação sistematizada das manifestaçōes de comportamento do doente. Nas observaçōes dos pacientes assistidos pelos nossos alunos, foi utilizado o roteiro para obervação elaborado por ARANTES (1968). Com os dados obtidos, tentamos fazer uma descrição geral do comportamento de pessoas com psicose epiléptica.

O comportamento do paciente com psicose epiléptica depende do seu estado emocional, pois tal doente apresenta grande labilidade de humor. t possivel que tenha lesões corporais, porque está sujeito a quedas. Em geral, veste-se com roupas de cores berrantes e, às vezes, demonstra preocupação excessiva com a limpeza corporal. Sua mímica facial pode expressar medo, cólera, preocupação ou tristeza. Ao executar alguma tarefa, detém-se em minúcias, desviando-se do objetivo central. Algumas vezes participa adequadamente de atividades junto a outros pacientes; outras, além de não terminar o que inicia, impede que os outros o façam, porque se põe a gritar, a agredir com recursos físicos ou verbais e tumultua o ambiente. Ao cumprimentar alguém, conserva a mão deste entre as suas durante tempo maior que o habitual, por vezes apertando-a seguidamente. Isso, quando não tenta abraçar ou beijar o outro ("o eterno abraço e aperto de mão do epiléptico"). Não tolera negativas a seus pedidos e, se assim acontece, pode sair correndo, gritar, xin- 
STEFANELLI, M.C. e Colaboradores - Assistência de enfermagem a paciente com comportamento decorrente de disritmia cerebral (psicose epiléptica). Rev. Bras. Enf.; DF, $30: 128-135,1977$.

gar ou bater nos que o cercam. O paciente diz que não gostam dele e que ninguém se interessa por sua pessoa. Fala incessantemente, com voz monótona, sem inflexão, denotando cansaço e pode começar a gritar de modo repentino. Descreve os fatos com minúcias e raramente chega ao tema central; repete sílabas, palavras e dificulta, ao interlocutor, acompanhar o curso do seu pensamento. Persiste no tema abordado, acrescentando-lhe detalhes desnecessários. As vezes, interrompe bruscamente o seu relato ou atividade e retoma-os a seguir, parecendo não perceber o ocorrido. Quando apresenta alucinações, relata o seu conteúdo que é, geralmente, terrífico. Idéias delirantes podem surgir e, em geral, estão relacionadas a sentimentos de inferioridade e prejuízo. As vezes, pode não saber localizar-se no tempo e espaço. Não admite a sua doença, isto é, "o ser epiléptico", e conseqüentemente aparenta dificuldade em aceitar internação e tratamento. Pode queixar-se de insônia, medo, sono agitado, tonturas, cefaléia, dores musculares em decorrência da crise convulsiva que pode apresentar.

Com base nesses elementos, fornecidos pela observação de comportamento de pacientes com psicose epiléptica internados em hospital psiquiátrico, podemos identificar o processo convencionalmente chamado "personalidade epiléptica", que, segundo alguns autores citados por COELHO (1975), nada mais é que um conjunto de manifestações emocionais reativas decorrentes das dificuldades de adaptação ao meio. Entre os traços da personalidade epiléptica, encontram-se: perseveração (afetiva, volitiva, ideativa), bradipsiquia, estereotipia verbal, prolixidade, viscosidade (mental e afetiva), pensamento obscuro, estreitamento e obnubilação da consciência, labilidade de humor e afetividade explosiva (fácil irritabilidade, impulsividade), egocen- trismo e traços fóbicos. Segundo VALLEJO-NAGERA (1958), essas caracteristicas constituem-se nos transtornos psíquicos permanentes e, para EY e colaboradores (1969), no caráter do portador de epilepsia. A personalidade do epiléptico é tão marcante que percebemos traços seus até em literatura de ficção e em trabalhos de arte, nas obras' de DOSTOIEVSKI e nas de VAN GOGH, por exemplo. Esses transtornos são considerados comuns a todos os doentes com disritmia cerebral; e, quando tais doentes apresentam psicose epiléptica, manifestam, além dessas características, sintomas psicóticos: alucinações, idéias delirantes, ilusōes, traços obsessivo-compulsivos e outros.

O paciente com psicose epiléptica está sujeito a transtornos psíquicos paroxísticos, como: estupor epiléptico, estado crepuscular, delirio epiléptico e dromomania. Via de regra, é atendido em pronto-socorro; portanto, não recebe, aqui, tratamento de maior profundidade.

Não podemos deixar de considerar as manifestações somáticas especificas, como: náusea, tontura, cefaléia, e as neurológicas, como: crise convulsiva e estado de mal epiléptico.

Os traços da personalidade e os sıntomas do paciente epiléptico levam-no a um comportamento que acarreta problemas, não só para a equipe de enfermagem mas também para o próprio paciente; apesar do progresso da medicina e particularmente do da neuropsiquiatria, esses problemas persistem devido ao estigma da epilepsia.

Uma das primeiras dificuldades com que o enfermeiro se defronta, ao prestar assistência ao paciente com o comportamento acima descrito, são as idéias preconcebidas, verdadeiro tabu, que existem em relação à epilepsia. Esses preconceitos, fruto de crendices e influências místicas, levam as pessoas a acre- 
STEFANELLI, M.C. e Colaboradores - Assistência de enfermagem a paciente com comportamento decorrente de disritmia cerebral (psicose epiléptica). Rev. Bras. Enf.; DF, $30: 128-135,1977$.

ditarem no contágio pela saliva (baba do epiléptico), na atraçāo de desgraças, na agressão a familiares e patrōes e na destruição de tudo ao seu redor - idéias que exercem influência na vida familial, escolar, social e, até, na profissional. No meio familial, como no escolar, os comportamentos predominantes sāo de superproteçāo, rejeiçāo ou repulsa pelo epiléptico. Na vida profissional: se os empregadores tomam conhecimento de que a pessoa sofre de epilepsia, relutam em empregá-lo ou, se já estiver trabalhando, em mantê-la no emprego; isso faz com que ela se sinta estigmatizada, escondendo a doença aos demais e, muitas vezes, chegando a abandonar o tratamento, caso tenha que ser feito na presença de outros. O oposto também pode ocorrer, isto é, o paciente aproveitar-se da situação, recorrendo ao auxíliodoença ou, o que é mais grave, tendendo à ociosidade e à mendicidade. Atualmente, esse temor parece mais relacionado com o desconhecido, que ainda se encontra sob a influência daqueles preconceitos. LENNOX 1 (1953) enfatiza-o bem: "Os demônios estāo agora mortos, mas o medo que inspiram durante séculos, quando viviam na mente do homem, pode ainda persistir como um tipo de pensamento embrionário que repousa no inconsciente do indivíduo moderno. $O$ que mais poderia explicar o horror irracional que sente pelas convulsões?"

Esses preconceitos constituem forte barreira na aceitaçāo do paciente como ser humano; e, também por causa deles, mesmo o próprio epiléptico expressa medo de sua doença. $\mathrm{E}$ angustiante, para - paciente e para a sua família, a necessidade de internaçāo em hospital psiquiátrico, pois, crêem eles, a disritmia é doença orgânica que prescinde de tratamento psiquiátrico. Como agravante somam-se, às limitações já impostas ao epiléptico e à pressāo que sofria do meio, os preconceitos contra a doença mental.

Outro grande problema do paciente já internado é a sua agressividade, aspecto que dificulta o relacionamento com o pessoal da equipe de enfermagem e com os demais. $E$ ainda: a dificuldade que o pessoal da equipe de enfermagem $e$ os demais têm em conseguir que o enfermo expresse o que está pensando ou sentindo.

Tudo isso acaba por ocasionar ansiedade e irritaçāo no pessoal da equipe de enfermagem e nos demais pacientes, o que resulta na rejeiçāo do epiléptico.

Portanto, um dos primeiros passos a serem dados pelo enfermeiro, ao assistir alguém com manifestações psiquiátricas decorrentes de disritmia cerebral, é superar os preconceitos e tabus em relação à epilepsia, para que chegue à aceitaçāo do paciente como pessoa. Isso conseguido e transmitida essa atitude aos demais membros da equipe e pacientes, entāo, sim, está ele em condições de começar a prestar uma assistência de enfermagem efetiva. Outra característica que o enfermeiro deve possuir ou desenvolver é o autodomínio, pois, como já vimos, o comportamento desse tipo de doente acarreta ansiedade e, até, medo a todos que o cercam. O traço de comportamento que mais intimida a todos e dificulta a adaptação do paciente ao ambiente hospitalar é a sua agressividade. Por isso, o enfermeiro deve ter sempre em mente que o enfermo com psicose epiléptica é um agressivo em potencial, em virtude de sua labilidade de humor e afetividade explosiva. $O$ início de suas alterações emocionais, muitas vezes, é desencadeado por estímulos externos: humanos e materiais. Habilidades pessoais, profissionais e recursos ma-

1. LENNOX citado por COELHO, L.M.S. Epilepsia e personalidade. São Paulo, Atica, 1975. p. 19-20. 
STEFANELI, M.C. e Colaboradores - Assistência de enfermagem a paciente com comportamento decorrente de disritmia cerebral (psicose epiléptica). Rev. Bras, Enf.; DF, 30 : 128-135, 1977.

teriais existentes são meios para um ade_ quado controle da agressividade, oferecendo proteção ao próprio paciente e aos demais. Na observação inicial de comportamento do doente, o enfermeiro encontrará dados indicadores dos estímulos que podem provocar-lhe alteraçōes emocionais. Fará, então, as mudanças necessárias e possíveis no ambiente, para evitar a existência desses estímulos. Mas, se perceber que o paciente está sofrendo a ação deles, deverá ficar atento para reconhecer manifestaçōes de agitação e para impedir que esta evolua para a agressividade.

Outra medida útil para controlar o comportamento do paciente é mantê-lo ocupado em atividades pragmáticas, para que possa sentir-se útil, capaz e desenvolva sua auto-estima, muito diminuída pelas pressões e rejeições sofridas. Por meio delas, podem-se descobrir novos interesses do doente e canalizálos para uma atividade profissional compatível com o seu estado.

Tendo em vista a socialização do paciente, o enfermeiro deverá ajudá-lo a comunicar o que pensa e sente, dirigindo o curso de seu pensamento para o objetivo central. Sempre que ele se desviar do assunto iniciado, o enfermeiro o levará a retomá-lo, auxiliando-o a expressar-se com clareza. Para tanto, o enfermeiro poderá repetir algum comentário feito anteriormente, utilizar frases em aberto, fazer perguntas relacionadas ao tema ou valer-se de outras técnicas para melhorar a comunicação verbal (HOFLING, 1970). Quando o enfermo narra os fatos de modo lento, o enfermeiro deve ter paciência, ouvir com atenção e, sendo necessário, dirigir a conversa. Se, ao relatar um fato ou cumprimentar alguém, o doente insiste no "eterno abraço e aperto de mão do eplléptico", convém colocar limites, dizendo, com clareza, que não há necessidade de comportar-se assim.
O paciente, em geral, tende a colocarse como centro da conversação; na hipótese de isso ocorrer, o enfermeiro introduzirá outros assuntos, não relacionados à pessoa do doente, mas do seu interesse.

Além dessas manifestaçōes, podem aparecer sintomas psicóticos vários, para os quais o enfermeiro deverá estar alerta. Os mais comumente encontrados são: alucinações (principalmente as visuais), idéias delirantes e ilusões. Quando o paciente os apresenta, a atuação principal do enfermeiro consiste em oferecer-lhe apoio, permanecendo ao seu lado e, caso necessário, protegendo-o, e aos demais, de possiveis agressões. Se apresentar alucinações, tentar trazê-lo à realidade e mantê-lo nela, chamando-o pelo nome, falando sobre assuntos concretos e, desde que preciso, tocando o seu ombro ou braço. Se o enfermo relatar a alucinação ou pedir confirmação sobre a existência de tais fenômenos, o enfermeiro deverá ouvir e dizer claramente que não está percebendo nada; mas, admitir que o paciente esteja percebendo, porque está doente. Tal conduta é um dos modos de levar a pessoa aceitar que está perturbada mentalmente, o que facilitará a aceitação da internação e do tratamento. Estes, como os Já citados anteriormente, constituem-se em sérios problemas para a equipe de enfermagem.

A llusão é um sintoma raro, mas pode ocorrer. A ação do enfermeiro será mostrar ao paciente que entende o fato dele interpretar erroneamente o que percebe; porém, tentar fazê-lo ver a situação real, de modo a não aumentar o seu nível de ansiedade: tocar os objetos, dizendo o que são, e, se possível, mostrar a sua utilidade. Caso tais llusões se sucedam com freqüência em relação a determinadas coisas, o enfermeiro deverá suprimi-las, quando der e for preciso.

Se o doente manifestar idéia delirante, a melhor conduta será deixar que 
STEFANEILI, M.C. e Colaboradores - Assistência de enfermagem a paciente com comportamento decorrente de disritmia cerebral (psicose epiléptica). Rev. Bras. Enf.; DF, $30: 128-135,1977$.

ele a apresente por um tempo determinado, porque tem necessidade de expressar o que sente e pensa. Entretanto, se insistir em falar apenas sobre ela, convirá que o enfermeiro estabeleça limites, introduzindo novos assuntos, ou que procure mantê-lo ocupado em atividades concretas. Não se deve discutir com o enfermo o coriteúdo delirioso de seus pensamentos, nem reforçá-lo. Cumpre ao enfermeiro reconhecer quando o paciente está em condições de começar a analisar suas idéias, fazendo com que o mesmo as critique e conclua que estão, de fato, fora da realidade. Não usar as icéias do doente para obter-lhe a cooperação e não deixar que o seu comportamento seja motivo de zombaria são questões que precisam ser bastante enfatiadas, quando se dá orientação ao pessoal dá equipe e aos demais pacientes.

E preciso estar sempre de prontidão para a ocorrência de uma crise convulsiva que poderá sobrevir a qualquer momento, independentemente do fato de o paciente estar sendo medicado. $O$ enfermeiro deverá prestar assistência específica para a crise, lembrando sempre que é possível que o doente entre em estado de mal epiléptico. Em alguns casos, sinais e sintomas característicos levam a prever que as convulsões ocorrerão; o enfermeiro deverá ajudar o enfermo a identificá-las, de maneira a que ele próprio desenvolva o seu autocuidado imediato, isto é: deitar-se o mais rápido possivel ,afrouxar as roupas e chamar por alguém. Assim como a crise convulsiva, outros quadros súbitos podem surgir - estupor epiléptico, estado crepuscular, delírio epiléptico e dromomania para os quais é necessário que o enfermeiro esteja atento. Nesses casos, se não houver condiçōes humanas e materiais para o atendimento do paciente, o recurso será um pronto-socorro. Exigem também atenção as manifestações somáticas do doente: elas podem resultar da disritmia cerebral ou ser um fator desencadeante da crise convulsiva.

Mas, todos esses cuidados de enfermagem deixarão de ter valor, se o enfermeiro não fizer uma anotação descritiva e completa daquilo que é observado no comportamento do doente; isso, porque só assim poderão avaliar-se as mudanças ocorridas. Orientação de todo o pessoal da equipe é também requisito fundamental de uma assistência adequada ac paciente.

Outro ponto a ser posto em relevo é que a compreensão e a aceitação social são as principais necessidades da pessoa enferma; desde que satisfeitas, ela poderá tornar-se um elemento útil para a sociedade. Como esse é o objetivo último da assistência integral ao paciente, cabe ao enfermeiro dar, a respeito, uma orientação adequada à família, aos empregadores, aos professores e a todos os outros com quem o doente convive (Psiquiatria Comunitária). Espera-se que, assim, os participantes do convívio sócioprofissional ofereçam, ao enfermo, oportunidades de desenvolver-se como indivíduo responsável e capaz, desde que haja, da parte dele, aceitação das limitações impostas pela vivência epiléptica. Tal orientação deve ser iniciada, a partir do primeiro contato com o paciente e seus familiares.

O enfermeiro deverá interagir com as pessoas da família do paciente, para colher dados sobre o relacionamento dele no meio familial, escolar, profissional e social. Tentará obter informações sobre: comportamento do enfermo, antes e depois da doença; aceitação do paciente (em que grau ela ocorre); reação geral às primeiras manifestaçōes da doença; expectativa dos parentes em relação à internação, ao tratamento, ao prognóstico, à recuperação sócio-profissional; atividades exercidas pelo paciente e suas habilidades profissionais; hábitos seus em relação à recreação e 
STEFANELLI, M.C. e Colaboradores - Assistência de enfermagem a paciente com comportamento decorrente de disritmia cerebral (psicose epiléptica). Rev. Bras. Enf.; DF, $30: 128-135,1977$.

sono. O ideal seria que tais informes fossem obtidos junto a professores, empregadores e membros do círculo de amizades do doente - tarefa que não seria difícil, se houvesse mais recursos profissionais ou já dispuséssemos da Psiquiatria Comunitária.

Na orientação a ser dada ao paciente, aos familiares e, quando possível, à comunidade, o enfermeiro deverá ressaltar os aspectos que se seguem:

Aceitar o enfermo com as limitações que the foram impostas pela doença, estimulando ao máximo a sua independência mas nāo exigindo dele aquilo que nāo é capaz de fazer.

Seguir o tratamento prescrito, para que, apesar das limitações, o paciente possa ter uma vida normal. Nāo interromper ou abandonar o trabalho sem ordem médica, pois poderá ocorrer crise convulsiva ou mesmo estado de mal epiléptico. Observar com rigor se o doente está ingerindo realmente a medicação, porque ele poderá estocar medicamentos para, tomando-os de uma só vez, tentar o suicídio. Se o tratamento for baseado em derivados do fenobarbital, avisar que pode haver sangramento gengival; nesse ca.so, dispensar maior atenção à higiene oral. Após a alta, comparecer às consultas marcadas e, se possivel, trazer consigo um relatório do seu comportamento feito pelos familiares; nele os membros da equipe encontrarāo elementos para melhor avaliaçāo do tratamento.
Quanto à vida profissional, nāo exercer atividades que provoquem desgaste físico excessivo; nāo trabalhar em andaimes, com caldeiras ou com materiais cortantes; não dirigir veículos e evitar qualquer tipo de trabalho que coloque em risco a sua integridade ou a dos outros. Se o paciente já desempenhar tais funções, sugerir ao empregador que aproveite as habilidades do empregado em setores que nāo ofereçam perigo.

Regrar a vida social e recreativa do paciente, para evitar que um desgaste físico e emocional exaustivo se constitua em fator desencadeante da repetiçāo dos surtos. O doente nāo deverá ingerir bebida alcoólica, nem mesmo socialmente, porque isso é capaz de prejudicar o tratamento e, se o seu caso for de convulsões, aquela ingestāo pode provocar uma crise convulsiva.

Lembrar, ainda, que é possível que o enfermo apresente qualquer dos sintomas ou quadros clínicos descritos anteriormente. Se assim ocorrer, procurar assistência médica imediatamente; mas os primeiros cuidados a serem prestados ao doente devem fazer parte da orientação à família.

útil ao paciente sempre trazer consigo um cartāo de identificaçāo, contendo: nome, endereço, telefone, pessoa a ser avisada, diagnóstico e primeiros socorros a serem dispensados.

Concluímos, insistindo: A reabilitaçāo do paciente relaciona-se, diretamente, com a aceitação dele pela sociedade.

\section{REFERENCIA BIBLIOGRÁFICA}

ARANTES, E. C. Observação de comportamento de pacientes internados em hospital psiquíatrico. Revista Brasileira de Enfermagem, 21 (1 e 2-3): 39-49, jan./fev./abr./jun. 1968.

ARANTES, E. C. Observação de comportamento de doentes mentais hospitalizados: (Tese - Escola de Enfermagem da USP). São Paulo, 1972.
BROWN, M. M. \& FOWLER, G. R. Psychodynamic nursing: a biosocial orientation. 4. ${ }^{\mathrm{a}}$ ed. Philadelphia, Saunders 1971. p. 79-87.

COELHO, L. M. S. Epilepsia e' personalidade. São Paulo, Atica, 1975. p. 17-77 e 456-89.

EY, H. et al. Tratado de psiquiatría. Barcelona, Toray - Masson, 1969. p. 341-5 
STEFANELLI, M.C. e Colaboradores - Assistência de enfermagem a paciente com comportamento decorrente de disritmia cerebral (psic zse epiléptica). Rev. Bras. Enf.; DF, $30: 128-135,1977$.

GARANT, C. A basic for care. Am. J. Nurs., 72 (4): 699-701, apr. 1972.

HOFLING, C. K. et al. Enfermeria psiquiátrica. 2. ed. México, Interamericana 1970. p. 3, 39-40 e 262-96.

SLAVINSKY, A. T. et al. Training nursing personnel to use a ratting scale. Perspect. Psychiatr. Care, 7 (5) : 214-21 sept./oct. 1969.

STEFANELLI, M. C. \& ARANTES, E. C Descrição das manifestaçōes de comportamento apresentado por pacientes com diagnóstico de esquizofrenia. Re- vista Brasileira de Enfermagem, 28 (4) : 9-21, out./dez. 1975.

TRAVELBEE, J. Intervention in psychiatric nursing: process in the one-to-one relationship. Philadelphia, Davis, 1969 p. 28-31.

TUDOR, G. E. A sociopsychiatric nursing approach to intervention in a problem of mutual withdrawal on a mental hospital ward. Perspect. Psychiatr. Care, 8 (1): 11-35, 1970.

VALLEJO-NAGERA, A. Lecciones de psiquiatría. 6." ed. Madrid, CientificoMédica, 1958, p. 207-9.

\section{BIBLIOGRAFIA}

FREITAS, J. O. de Aspectos da condição social dos epllépticos. In: Estudos neuro-psiquiátricos. São Paulo, Arqulmedes, 1969. p. 101-26.

GARCIA, J. A. Aspectos clínicos, psiquiátricos e médico-sociais da epilepsia. Revista Brasileira de Psiquiatria, 1 (2) : 147-58, dez. 1967.

JOHINTON, M. K. Mental health \& mental illness. Philadelphia, Lippincott, 1971. p. 186-197.
MARTINS, C. Aspectos psicopatológicos das epilepsias temporais - o problema do diagnóstico clínico. Revista Brasileira de Psiquiatria, 1 (2): 168-72, dez. 1967.

PONTE, A. W. de $A$. Os mitos da epilepsia - suas origens e sua importáncia. Revista Brasileira de Psiquiatria, 1 (2) : 93-7, dez. 1967.

SANTO-DOMINGO CARRASCO, J. Elementos de psiquiatria y assistencia psiquiátrica. Barcelona, Cientifico-Médica, 1968. p. 103-21. 